\title{
Interação ractopamina e hormônio do crescimento no metabolismo de ratas hipofisectomizadas
}

\author{
Bianca Sacramento Barros ${ }^{1}$ \\ Filipe Curti ${ }^{1}$ \\ Leonardo Rafael da Silva ${ }^{1}$ \\ Tauany Costa ${ }^{1}$ \\ Raquel Vieira Lobato ${ }^{1}$ \\ Luciano José Pereira ${ }^{1}$ \\ Márcio Gilberto Zangerônimo ${ }^{1}$ \\ Marcelo Eustáquio Silva ${ }^{2}$ \\ Raimundo Vicente de Sousa ${ }^{1 *}$ \\ ${ }^{1}$ Universidade Federal de Lavras, Campus Universitário \\ Caixa Postal 3037, CEP 37200-000, Lavras - MG, Brasil \\ ${ }^{2}$ Departamento de Nutrição \\ Universidade Federal de Ouro Preto, Ouro Preto - MG, Brasil \\ *Autor para correspondência \\ rvsousa@dmv.ufla.br
}

Submetido em 26/06/2013

Aceito para publicação em 03/10/2013

\section{Resumo}

A ractopamina e o hormônio do crescimento têm sido muito estudados por conta de sua capacidade de gerar uma melhor partição de nutrientes no organismo, proporcionando aumento na síntese proteica muscular e lipólise no tecido adiposo. Assim, este artigo tem por objetivo verificar os efeitos da interação entre essas substâncias no metabolismo de ratas hipofisectomizadas e seus efeitos individuais sobre a composição corporal desses animais. Trinta ratas Fisher foram distribuídas em cinco tratamentos, sendo um grupo controle normal, um controle hipofisectomizado e os outros três grupos de animais hipofisectomizados tratados com ractopamina (80 $\mathrm{mg} / \mathrm{kg} / \mathrm{dia})$, com hormônio do crescimento (4 mg/kg/dia) e com a associação dos dois, todos com seis repetições em cada grupo. A associação das duas substâncias proporcionou maior porcentagem de proteína e diminuição do extrato etéreo na carcaça dos animais. Além disso, ocasionou aumento na ingestão de água, na produção urinária e diminuição do peso relativo dos rins, fígado e baço quando comparado ao grupo controle. $\mathrm{O}$ uso do hormônio do crescimento proporcionou maior ganho de peso final e eficiência alimentar, menor peso cardíaco e aumento da glicemia, e o uso da ractopamina ocasionou maior peso pulmonar, aumento no colesterol total e IGF-1 e diminuição na concentração de peptídeo C.

Palavras-chave: Hormônio do crescimento; Ractopamina; Ratas 


\section{Abstract}

Interaction between ractopamine and growth hormone in the metabolism of hypophysectomized female rats. Ractopamine and growth hormone have been extensively studied due to their ability to generate a better partition of nutrients in the body, providing an increased muscle protein synthesis and lipolysis in adipose tissue. Thus, this article aims to check the effects of interaction between these substances on the metabolism of hypophysectomized female rats, and their individual effects on the body composition of these animals. Thirty Fisher rats were distributed into five treatments, one of them was a normal control group, one was a hypophysectomized control group, and the other three were hypophysectomized animal groups treated with ractopamine $(80 \mathrm{mg} / \mathrm{kg} / \mathrm{day})$, with growth hormone $(4 \mathrm{mg} / \mathrm{kg} /$ day $)$, and with a combination of them, all with six replicates in each group. The association between these substances provided a higher percentage of protein and decreased ether extract in the animals' carcass. Furthermore, it caused an increase in water intake, in urine production, and decreased relative weight of kidneys, liver, and spleen when compared to the control group. The use of growth hormone provided a higher final weight gain and feeding effectiveness, lower heart weight and increased blood glucose level, and the use of ractopamine resulted in a higher lung weight, increased total cholesterol and IGF-1, and decreased peptide C concentration.

Key words: Growth hormone; Ractopamine; Female rats

\section{Introdução}

A ractopamina (RAC) agonista beta-adrenérgico pertencente à família das fenetanolaminas, é análoga estrutural de hormônios coletivamente denominados catecolaminas (epinefrina e norepinefrina) (MERSMANN, 2002; MILLS et al., 2003). Esse agonista de receptor beta-adrenérgico é também classificado como promotor de crescimento, por ser capaz de gerar uma melhor partição de nutrientes do tecido adiposo em favor do crescimento muscular (APPLE et al., 2007; WATANABE et al., 2011).

Um dos efeitos mais conhecidos da ractopamina em suínos e bovinos é o incremento da musculatura esquelética pelo aumento da síntese proteica e/ou decréscimo de sua degradação (SEE et al., 2004; GONZALEZ; SILVA, 2006). Além disso, a RAC reduz a sensibilidade à insulina nos adipócitos, o que causa uma diminuição desses, reduzindo assim sua capacidade de armazenamento de gordura (HAUSMAN et al., 1989; DUBROVIN et al., 1990; MERSMANN, 2002; MILLS, 2002). No entanto, estudos in vitro, evidenciam que os agonistas beta-adrenérgicos aumentam a produção de AMPc (Monofosfato cíclico de adenosina), levando a ativação de quinases que fosforilam a lipase, hormônio sensível, estimulando assim a lipólise (LIU; MILLS, 1990; LIU et al., 1994; MOODY et al., 2000). Em ratos foi verificado que a RAC aumenta a apoptose no tecido adiposo branco e isso pode ser uma boa justificativa para o fato dos suínos apresentarem carcaças com menor quantidade de gordura (PAGE et al., 2004; WEBER et al. 2006). Seus efeitos variam com a duração do tratamento de forma que com 14 a 21 dias ocorre uma melhora nas condições da carcaça e após isso, essa melhora somente se mantém (KIM et al., 1990).

O hormônio do crescimento $(\mathrm{GH})$ é o principal regulador do crescimento no organismo e é produzido pelas células chamadas de Somatrotofos, localizadas na Adeno-hipófise. Existem receptores de $\mathrm{GH}$ em diversos tecidos, tais como músculo esquelético, fígado, rins, pâncreas, coração, intestino, pulmão e cérebro (CRUZAT et al., 2008).

$\mathrm{O}$ GH atua realizando funções no organismo de maneira direta ou indireta, por meio da produção das somatomedinas (IGF-1 e IGF-2). Dentre essas funções pode-se citar o aumento do crescimento linear dos ossos, da síntese proteica nos músculos, da lipólise no tecido adiposo, além de causar no organismo um efeito hiperglicemiante ou diabetogênico (CRUZAT et al., 2008; ENGELKING, 2011).

A somatomedina $\mathrm{C}$ ou IGF-1 é um polipeptídeo cuja sequência de aminoácidos é bem parecida com a da pró-insulina e exerce efeitos semelhantes aos da insulina, por exemplo, sobre o crescimento e sobre a homeostase da glicose (ROSENDAL et al., 2002; FRYSTYK, 2004). 
Esse hormônio pode atuar nos seus devidos receptores, localizados nos diversos órgãos, inclusive hipotálamo e hipófise, e também em receptores de insulina dependendo da sua concentração (BUONOMO; BAILE, 1990; MAURAS; HAYMOND, 2005).

De acordo com Oliveira et al. (2011), o IGF-I é produzido no fígado e em vários outros órgãos. Esse hormônio é secretado pelo fígado em resposta à estimulação do hormônio do crescimento $(\mathrm{GH})$ e é o mais potente estimulador da síntese proteica (BAUER et al., 2009) sendo considerado o grande mediador dos efeitos anabólicos do GH (CRUZAT et al., 2008).

No metabolismo de lipídios e composição corporal, o GH possui receptores específicos no tecido adiposo causando lipólise pelo aumento da atividade da lipase hormônio sensível, além de aumentar a eficiência dos receptores beta-adrenérgicos (CRUZAT et al., 2008). No fígado e no músculo, o GH estimula a captação de triacilglicerois e seu armazenamento, pois ativa a lipase lipoproteica (VIJAYAKUMAR et al., 2010).

No metabolismo de carboidratos, o GHé responsável pelo efeito diabetogênico, e causa também glicogenólise no fígado. O IGF possui efeitos semelhantes à insulina, o que gera uma hipoglicemia e uma diminuição de insulina circulante (LIU; MILLS, 1990; MAURAS; HAYMOND, 2005; DEL RINCON et al., 2007; CRUZAT et al., 2008; VIJAYAKUMAR et al., 2010).

O IGF hepático normalmente está relacionado com crescimento de diversos tecidos como o ósseo e o muscular enquanto que o IGF extra-hepático, o qual tem estímulo predominantemente autócrino e parácrino não possuem efeitos totalmente esclarecidos (OLIVEIRA et al., 2011).

Diante do exposto objetivou-se verificar os efeitos da interação da ractopamina e do GH no metabolismo de ratas hipofisectomizadas, bem como verificar o efeito da ractopamina e do GH individualmente sobre a composição corporal desses animais.

\section{Material e Métodos}

O presente experimento foi aprovado pelo Comitê de Ética da Universidade Federal de Lavras sob o protocolo no ${ }^{-009 / 12 . ~}$
Foram utilizadas 30 ratas Fisher jovens com idade aproximada de 60 dias e peso inicial de $200 \pm 40 \mathrm{~g}$, as quais foram mantidas individualmente em gaiolas metabólicas, no setor de Fisiologia e Farmacologia do Departamento de Medicina Veterinária da Universidade Federal de Lavras, com temperatura controlada a \pm $22^{\circ} \mathrm{C}$ e luminosidade em ciclo $12 \mathrm{~h} / 12 \mathrm{~h}$. Esses animais receberam ração comercial para roedores e água $a d$ libidum.

Os animais adquiridos foram aleatoriamente divididos em cinco grupos experimentais contendo seis animais em cada grupo: um grupo controle formado pelos animais não hipofisectomizados e não tratados com ractopamina e/ou $\mathrm{GH}$; um grupo formado por animais hipofisectomizados que também não receberam tratamento com ractopamina e/ou GH; um grupo experimental contendo animais hipofisectomizados e tratados com ractopamina na dose de $80 \mathrm{mg} / \mathrm{kg} /$ dia por gavagem (PAGE et al., 2004); um grupo experimental contendo animais hipofisectomizados tratados com GH na dose de $4 \mathrm{mg} / \mathrm{kg} /$ dia via subcutânea (JOHANSEN; LAURINO, 2005) e um grupo experimental contendo animais hipofisectomizados tratados com ractopamina e GH nas doses de $80 \mathrm{mg} / \mathrm{kg} /$ dia por gavagem e $4 \mathrm{mg} /$ $\mathrm{kg} /$ dia via subcutânea respectivamente, sendo que a ractopamina foi dividida em duas doses diárias e o $\mathrm{GH}$ administrado em dose única pela manhã.

Para a hipofisectomia vinte e quatro ratas foram anestesiadas com quetamina na dose de $50 \mathrm{mg} / \mathrm{kg}$ e xilazina na dose de $20 \mathrm{mg} / \mathrm{kg}$ e posteriormente hipofisectomizadas segundo a técnica transauricular de Sato e Yoneda (1966, apud CERANOWICZ et al., 2010; SUGA et al., 2011).

Após a hipofisectomia todos os animais receberam tratamento com antibiótico à base de Sulfametoxazol e Trimetropim (Trissulfin ${ }^{\circledR}$ ) duas vezes ao dia por sete dias, anti-inflamatório à base de Meloxican (Maxican ${ }^{\circledR}$ ) uma vez ao dia por três dias nas doses de $30 \mathrm{mg} / \mathrm{kg}$ e 2 $\mathrm{mg} / \mathrm{kg}$ por via subcutânea. No dia seguinte ao término da administração do antibiótico, os animais passaram a receber doses de $80 \mathrm{mg} / \mathrm{kg} /$ dia de ractopamina via oral por gavagem e/ou $4 \mathrm{mg} / \mathrm{kg}$ de GH via subcutânea, sendo a ractopamina dividida a cada $12 \mathrm{~h}$ e o $\mathrm{GH}$ administrado em dose única pela manhã, durante um período de 14 dias. 
Os seis animais restantes que não foram hipofisectomizados também receberam tratamento com antibiótico e anti-inflamatório.

Os animais foram pesados a cada sete dias e seu consumo alimentar, consumo de água e volume de urina foram medidos diariamente.

Ao final do período experimental, todos os animais ficaram em jejum por $12 \mathrm{~h}$ e foram eutanasiados por meio da administração de Tiopental via intraperitoneal na dose de $80 \mathrm{mg} / \mathrm{kg}$, para a coleta do sangue e dos órgãos que foram analisados.

O sangue foi coletado por punção cardíaca e o plasma e o soro foram armazenados a $-20^{\circ} \mathrm{C}$ para posterior avaliação das concentrações séricas de glicose, triacilglicerois, colesterol total, peptídeo C e IGF-1.

Foram coletados coração, fígado, baço, pulmão, intestinos e rins, para a avaliação do peso relativo dos órgãos. Na composição centesimal da carcaça foram avaliadas proteína, extrato etéreo, cinzas e umidade pelo método da Association of Official Analytical Chemists.

A glicose, os triacilglicerois e o colesterol total foram quantificados por kits enzimáticos colorimétricos da empresa DOLES ${ }^{\circledR}$. A concentração de IGF-1 foi analisada pelo método ELISA usando-se o kit comercial DRG $^{\circledR}$ IGF-1 600 ELISA, e o de peptídeo C analisado pelo kit comercial Enzyme-linked Immunosorbent Assay Kit for Peptide C E90447Ra ${ }^{\circledR}$ Uscn.

Os dados foram submetidos à análise de variância, sendo as médias obtidas com a ractopamina e $\mathrm{GH}$ comparadas entre si pelo teste $\mathrm{F}$ e em relação ao controle pelo teste Dunnet. A variação de peso, variação média diária de peso e a eficiência alimentar foram analisadas pelo teste não paramétrico de Kruskal-Walis. O nível de significância adotado para esse trabalho foi de ( $\mathrm{p} \leq$ $0,05)$. Todas as análises estatísticas foram realizadas no programa Action 2.4.

\section{Resultados}

O uso do $\mathrm{GH}$ proporcionou $(\mathrm{p}<0,05)$ maior ganho de peso final e eficiência alimentar quando comparado aos animais que não foram tratados com o hormônio.
Os animais hipofisectomizados obtiveram $(p<0,05)$ valores no ganho de peso diferentes do controle, sendo que os valores maiores se referem aos tratamentos com o hormônio (Tabela 1).

A associação do GH e da ractopamina proporcionou $(\mathrm{p}<0,05)$ maior consumo de ração diária quando comparada ao uso individual da ractopamina. O uso da ractopamina diminuiu $(\mathrm{p}<0,05)$ o rendimento da carcaça, independente do uso do GH (Tabela 1).

A produção urinária dos grupos hipofisectomizados foi maior quando comparada à produção do grupo controle não hipofisectomizado ( $\mathrm{p}<0,05)$. A associação de $\mathrm{GH}$ com ractopamina aumentou $(\mathrm{p}<0,05)$ o consumo de água e a produção urinária, em relação ao controle, porém o mesmo efeito não foi observado quando usadas as duas substâncias separadamente (Tabela 1).

O peso relativo do coração apresentou $(\mathrm{p}<0,05)$ diferença quando comparado aos grupos tratados com GH e/ou ractopamina ao grupo controle, o qual apresentou peso cardíaco maior. $\mathrm{O}$ uso do hormônio de crescimento proporcionou $(\mathrm{p}<0,05)$ um menor peso cardíaco quando comparado aos animais que não receberam o GH (Tabela 2).

O peso relativo do fígado e do baço dos animais hipofisectomizados, tratados com GH e/ou ractopamina, foi menor quando comparado $(\mathrm{p}>0,05)$ aos animais do grupo controle não hipofisectomizados. $\mathrm{O}$ uso de $\mathrm{GH}$ proporcionou $(\mathrm{p}<0,05)$ um maior peso do baço em relação aos animais que não utilizaram o GH (Tabela 2).

Os animais não tratados com $\mathrm{GH}$ e os animais tratados com ractopamina apresentaram $(\mathrm{p}<0,05)$ maior peso relativo do pulmão quando comparados aos animais tratados com GH e não tratados com ractopamina (Tabela 2 ).

O uso da ractopamina proporcionou $(\mathrm{p}<0,05) \mathrm{um}$ aumento no peso relativo do intestino quando comparado aos animais não tratados (Tabela 2).

Os grupos de animais tratados com $\mathrm{GH}$ e/ou ractopamina apresentaram $(\mathrm{p}<0,05)$ menor peso relativo dos rins quando comparados ao grupo controle não hipofisectomizado (Tabela 2). 
TABELA 1: Variação de peso, consumo de ração, consumo de água e volume urinário de animais hipofisectomizados tratados com ractopamina e $\mathrm{GH}$.

\begin{tabular}{|c|c|c|c|c|c|c|c|}
\hline \multirow{2}{*}{ Ractopamina } & \multicolumn{4}{|c|}{ GH } & & \multirow{2}{*}{ Média } & \multirow{2}{*}{ CV $(\%)$} \\
\hline & & Com & & sem & & & \\
\hline \multicolumn{8}{|c|}{ 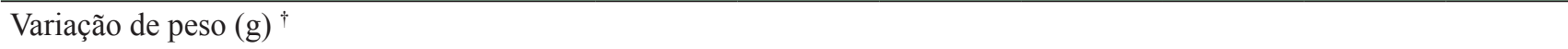 } \\
\hline Com & $50,0 *$ & & $-2,7 *$ & & 23,7 & & - \\
\hline Sem & $37,3^{*}$ & & $-0,2 *$ & & 18,6 & & \\
\hline Média & $43,7 \mathrm{a}$ & & $-1,4 b$ & & & & \\
\hline Controle & 12,8 & & & & & & \\
\hline \multicolumn{8}{|c|}{ Consumo de ração diário $(\mathrm{g})$} \\
\hline Com & 15,77 a & & $12,27 \mathrm{~b}^{*}$ & & 14,02 & & 13,64 \\
\hline Sem & 14,49 & & 14,32 & & 14,40 & & \\
\hline Média & 15,13 & & 13,30 & & & & \\
\hline Controle & 16,08 & & & & & & \\
\hline \multicolumn{8}{|c|}{ Eficiência alimentar $^{\dagger}$} \\
\hline Com & $0,230^{*}$ & & $-0,016$ & & 0,107 & & - \\
\hline Sem & $0,187^{*}$ & & $-0,003$ & & 0,092 & & \\
\hline Média & $0,208 \mathrm{a}$ & & $-0,010 b$ & & & & \\
\hline Controle & 0,056 & & & & & & \\
\hline \multicolumn{8}{|c|}{ Rendimento de Carcaça (g) } \\
\hline Com & 79,47 & & 78,87 & & $79,17 \mathrm{~B}$ & & 2,66 \\
\hline Sem & 80,46 & & 82,11 & & $81,29 \mathrm{~A}$ & & \\
\hline Média & 79,97 & & 80,49 & & & & \\
\hline Controle & 78,79 & & & & & & \\
\hline \multicolumn{8}{|c|}{ Consumo de água diário (ml) } \\
\hline Com & $67,2 \mathrm{Aa}^{*}$ & & $39,4 \mathrm{~b}$ & & 53,3 & & 10,40 \\
\hline Sem & $36,9 \mathrm{~B}$ & & 35,7 & & 36,3 & & \\
\hline Média & 52,0 & & 37,5 & & & & \\
\hline Controle & 25,5 & & & & & & \\
\hline \multicolumn{8}{|c|}{ Volume Urinário diário $(\mathrm{ml})$} \\
\hline Com & 42,4 $\mathrm{Aa}^{*}$ & & $13,7 b^{*}$ & & 28,1 & & 23,04 \\
\hline Sem & $18,9 \mathrm{~B} *$ & & $15,7^{*}$ & & 17,3 & & \\
\hline Média & 30,7 & & 14,7 & & & & \\
\hline Controle & 0,4 & & & & & & \\
\hline
\end{tabular}

${ }^{a, b}$ Médias seguidas por diferentes letras minúsculas na linha e maiúsculas na coluna diferem pelo teste $\mathrm{F}(\mathrm{p}<0,05)$. ${ }^{*}$ Difere do controle pelo teste Dunnett $(\mathrm{p}<0,05) .{ }^{\dagger}$ Médias diferem pelo teste de Kruskal-Wallis $(\mathrm{p}<0,05)$. CV= Coeficiente de variação. 
TABELA 2: Peso relativo de órgãos de animais hipofisectomizados tratados com ractopamina e hormônio de crescimento $(\mathrm{GH})$.

\begin{tabular}{|c|c|c|c|c|}
\hline \multirow{2}{*}{ Ractopamina } & \multicolumn{2}{|c|}{ GH } & \multirow{2}{*}{ Média } & \multirow{2}{*}{$\mathrm{CV}(\%)$} \\
\hline & Com & sem & & \\
\hline \multicolumn{5}{|l|}{ Coração (\%) } \\
\hline Com & $0,292^{*}$ & $0,314^{*}$ & 0,303 & 15,98 \\
\hline Sem & $0,309^{*}$ & 0,370 & 0,339 & \\
\hline Média & $0,300 \mathrm{~b}$ & $0,342 \mathrm{a}$ & & \\
\hline Controle & 0,370 & & & \\
\hline \multicolumn{5}{|l|}{ Fígado (\%) } \\
\hline Com & $3,64^{*}$ & $3,54^{*}$ & 3,59 & 10,79 \\
\hline Sem & $3,52 *$ & $3,40 *$ & 3,46 & \\
\hline Média & 3,58 & 3,47 & & \\
\hline Controle & 4,04 & & & \\
\hline \multicolumn{5}{|l|}{ Baço (\%) } \\
\hline Com & $0,229^{*}$ & $0,170^{*}$ & 0,199 & 8,48 \\
\hline Sem & $0,231^{*}$ & $0,211^{*}$ & 0,221 & \\
\hline Média & $0,230 \mathrm{a}$ & $0,190 \mathrm{~b}$ & & \\
\hline Controle & 0,312 & & & \\
\hline \multicolumn{5}{|l|}{ Pulmão (\%) } \\
\hline Com & 0,849 & 1,005 & $0,927 \mathrm{~A}$ & 10,71 \\
\hline Sem & 0,736 & 0,808 & $0,772 \mathrm{~B}$ & \\
\hline Média & $0,792 \mathrm{~b}$ & $0,907 \mathrm{a}$ & & \\
\hline Controle & 0,790 & & & \\
\hline \multicolumn{5}{|l|}{ Intestino (\%) } \\
\hline Com & 8,32 & $8,97 \mathrm{~A}$ & 8,64 & 14,20 \\
\hline Sem & 8,03 & $6,93 \mathrm{~B}$ & 7,48 & \\
\hline Média & 8,17 & 7,95 & & \\
\hline Controle & 7,94 & & & \\
\hline \multicolumn{5}{|l|}{ Rins (\%) } \\
\hline Com & $0,642 *$ & $0,609^{*}$ & 0,625 & 14,63 \\
\hline Sem & $0,642 *$ & 0,760 & 0,701 & \\
\hline Média & 0,642 & 0,685 & & \\
\hline Controle & 0,860 & & & \\
\hline
\end{tabular}

a,b Médias seguidas por diferentes letras minúsculas na linha e maiúsculas na coluna diferem pelo teste $\mathrm{F}(\mathrm{p}<0,05)$ * Difere do controle pelo teste Dunnett $(\mathrm{p}<0,05) . \mathrm{CV}=$ Coeficiente de variação. 
Os grupos de animais tratados com ractopamina e/ ou GH apresentaram $(p<0,05)$ maior porcentagem de proteína quando comparados ao grupo controle. O uso da ractopamina aumentou $(\mathrm{p}<0,05)$ a porcentagem de proteína na carcaça dos animais quando comparada aos animais que não a receberam (Tabela 3 ).

$\mathrm{O}$ uso da ractopamina e do $\mathrm{GH}$ de forma independente aumentou $(\mathrm{p}<0,05)$ a porcentagem da umidade e diminuiu $(\mathrm{p}<0,05)$ a porcentagem do extrato etéreo da carcaça dos animais. Os animais tratados com ractopamina e GH apresentaram $(p<0,05)$ menor porcentagem de extrato etéreo quando comparado ao grupo controle não hipofisectomizado (Tabela 3).

O uso da ractopamina proporcionou $(\mathrm{p}<0,05) \mathrm{um}$ aumento no colesterol total quando comparado ao grupo que não usou a substância e ao grupo controle (Tabela 4).
A concentração de triacilglicerois no sangue foi menor nos animais tratados com ractopamina associada ao $\mathrm{GH}$, porém, o mesmo efeito não foi observado nos animais que foram tratados somente com $\mathrm{GH}(\mathrm{p}<0,05)$ (Tabela 4).

Os animais hipofisectomizados apresentaram $(\mathrm{p}<$ $0,05)$ diferença na glicemia quando comparados ao grupo controle não hipofisectomizado. Os animais tratados com GH tiveram $(\mathrm{p}<0,05)$ um aumento significativo na glicose sanguínea quando comparado aos animais não tratados, ao contrário dos animais tratados com ractopamina que apresentaram $(\mathrm{p}<0,05)$ uma diminuição na concentração de glicose quando comparado aos grupos não tratados com a substância (Tabela 4).

Os animais tratados com ractopamina e não tratados com GH apresentaram $(p<0,05)$ maiores concentrações

TABELA 3: Composição da carcaça de animais hipofisectomizados tratados com ractopamina e hormônio do crescimento $(\mathrm{GH})$.

\begin{tabular}{|c|c|c|c|c|}
\hline \multirow{2}{*}{ Ractopamina } & \multicolumn{2}{|c|}{ GH } & \multirow{2}{*}{ Média } & \multirow{2}{*}{$\mathrm{CV}(\%)$} \\
\hline & Com & sem & & \\
\hline \multicolumn{5}{|l|}{ Umidade (\%) } \\
\hline Com & 72,5 & 70,0 & $71,2 \mathrm{~B}$ & 4,91 \\
\hline Sem & 69,1 & 68,8 & $68,9 \mathrm{~A}$ & \\
\hline Média & $70,8 \mathrm{~b}$ & $69,4 \mathrm{a}$ & & \\
\hline Controle & 69,2 & & & \\
\hline \multicolumn{5}{|c|}{ Proteína Bruta (\%) } \\
\hline Com & $21,4 *$ & $21,1 *$ & $21,2 \mathrm{~A}$ & 5,66 \\
\hline Sem & $20,6^{*}$ & 19,9 & $20,2 \mathrm{~B}$ & \\
\hline Média & 21,0 & 20,5 & & \\
\hline Controle & 18,7 & & & \\
\hline \multicolumn{5}{|l|}{ Cinzas (\%) } \\
\hline Com & 4,23 & 4,87 & 4,55 & 8,79 \\
\hline Sem & 4,47 & 4,91 & 4,69 & \\
\hline Média & 4,35 & 4,89 & & \\
\hline Controle & 4,54 & & & \\
\hline \multicolumn{5}{|c|}{ Extrato Etéreo (\%) } \\
\hline Com & $1,88^{*}$ & 5,32 & $3,60 \mathrm{~B}$ & 8,25 \\
\hline Sem & 6,70 & 9,65 & $8,17 \mathrm{~A}$ & \\
\hline Média & $4,29 \mathrm{~b}$ & $7,48 \mathrm{a}$ & & \\
\hline Controle & 6,24 & & & \\
\hline
\end{tabular}

${ }^{\mathrm{a}, \mathrm{b}}$ Médias seguidas por diferentes letras minúsculas na linha e maiúsculas na coluna diferem pelo teste $\mathrm{F}(\mathrm{p}<0,05)$ * Difere do controle pelo teste Dunnett $(\mathrm{p}<0,05)$. CV = Coeficiente de variação. 
TABELA 4: Colesterol total, triacilglicerois, glicose, IGF-1 e peptídeo C de animais hipofisectomizados tratados com ractopamina e hormônio do crescimento $(\mathrm{GH})$.

\begin{tabular}{|c|c|c|c|c|}
\hline \multirow{2}{*}{ Ractopamina } & \multicolumn{2}{|c|}{ GH } & \multirow{2}{*}{ Média } & \multirow{2}{*}{ CV $(\%)$} \\
\hline & Com & sem & & \\
\hline \multicolumn{5}{|c|}{ Colesterol Total (mg/dL) } \\
\hline Com & $182,1^{*}$ & $185,9 *$ & $184,0 \mathrm{~A}$ & 7,75 \\
\hline Sem & 155,8 & 169,3 & $162,6 \mathrm{~B}$ & \\
\hline Média & 168,9 & 177,6 & & \\
\hline Controle & 159,2 & & & \\
\hline \multicolumn{5}{|c|}{ Triacilglicerois (mg/dL) } \\
\hline Com & $159,2 \mathrm{~B}$ & 169,4 & 164,3 & 6,47 \\
\hline Sem & $178,1 \mathrm{~A}$ & 169,0 & 173,5 & \\
\hline Média & 168,6 & 169,2 & & \\
\hline Controle & 169,0 & & & \\
\hline \multicolumn{5}{|c|}{ Glicose (mg/dL) } \\
\hline Com & $61,3^{*}$ & $40,9^{*}$ & $51,1 \mathrm{~B}$ & 9,32 \\
\hline Sem & $110,3^{*}$ & $70,4^{*}$ & $90,4 \mathrm{~A}$ & \\
\hline Média & 85,8 a & $55,7 \mathrm{~b}$ & & \\
\hline Controle & 85,8 & & & \\
\hline \multicolumn{5}{|l|}{ IGF $1(\mathrm{ng} / \mathrm{mL})$} \\
\hline Com & 198,0 & 270,0 & $234,0 \mathrm{~A}$ & 10,15 \\
\hline Sem & 190,0 & 199,0 & $194,0 \mathrm{~B}$ & \\
\hline Média & $194,0 \mathrm{~b}$ & $234,0 \mathrm{a}$ & & \\
\hline Controle & 193,0 & & & \\
\hline \multicolumn{5}{|c|}{ Peptídeo C (ng/mL) } \\
\hline Com & 9,45 & 14,68 & $12,07 \mathrm{~B}$ & 18,25 \\
\hline Sem & 22,36 & 24,02 & $23,19 \mathrm{~A}$ & \\
\hline Média & 15,91 & 19,35 & & \\
\hline Controle & 14,73 & & & \\
\hline
\end{tabular}

a,b Médias seguidas por diferentes letras minúsculas na linha e maiúsculas na coluna diferem pelo teste $\mathrm{F}(\mathrm{p}<0,05)$ * Difere do controle pelo teste Dunnett $(\mathrm{p}<0,05)$. CV= Coeficiente de variação.

de IGF-1 quando comparado aos grupos tratados sem ractopamina e com GH (Tabela 4).

O uso da ractopamina diminuiu $(\mathrm{p}<0,05)$ a concentração de peptídeo $\mathrm{C}$ quando comparado aos grupos que não receberam a substância (Tabela 4).

\section{Discussão}

O hormônio de crescimento $(\mathrm{GH})$ atua no crescimento e na proliferação celular de diferentes tecidos além de gerar um aumento na capacidade de síntese proteica por atuar na expressão do RNA mensageiro ou redução da degradação e/ou aumento da absorção dos aminoácidos nos músculos (CRUZAT et al., 2008; VIJAYAKUMAR et al., 2010). Isso é condizente com o resultado observado neste experimento, onde os animais tratados com o GH apresentaram maior ganho de peso em comparação com os animais não tratados. Além disso, o maior ganho de peso ocorreu nos animais que receberam a associação da ractopamina e do $\mathrm{GH}$, o que provém do efeito de potencialização de receptores beta-adrenérgicos que o GH exerce sobre os receptores da ractopamina (MAURAS; HAYMOND, 2005). 
Quanto ao consumo de alimento, os animais que receberam a associação apresentaram maior consumo de alimento quando comparado aos animais que não receberam $\mathrm{GH}$, o que ocorre devido à maior demanda energética pelo aumento do ganho de peso. Com o uso de dois estimuladores de síntese proteica, o organismo tende a necessitar de uma quantidade maior de energia, aumentando assim o consumo de alimento. Esse mesmo efeito foi observado por Cantarelli (2007) em suínos, os quais aumentaram o consumo devido à fonte de energia limitada na dieta.

A eficiência alimentar foi maior nos grupos que utilizaram o GH. Essa diferença estatística pode estar associada com o ganho de peso dos animais, pois os animais que receberam $\mathrm{GH}$ apresentaram maior ganho de peso, consequentemente sua eficiência alimentar foi maior; e os animais que não receberam o hormônio apresentaram uma variação negativa de peso com consequente eficiência alimentar negativa.

Com relação ao rendimento de carcaça, houve diferença significativa entre os animais que receberam a ractopamina e os que não receberam. Uma hipótese para o grupo que não recebeu ractopamina estar com maior rendimento de carcaça pode estar relacionada com o peso intestinal, por ser o órgão interno mais pesado e que influencia o rendimento. Nesse caso os animais apresentaram maior peso intestinal devido à necessidade de captação de nutrientes pelo organismo para maior produção de proteína muscular (CANTARELLI, 2007). Os animais que tiveram o peso intestinal maior apresentaram menor rendimento de carcaça e vice-versa.

Animais hipofisectomizados apresentam além da deficiência do hormônio do crescimento, a deficiência do hormônio antidiurético, liberado pela Adenohipófise. Esse hormônio é responsável pelo controle da osmolaridade dos líquidos corporais. Ele é responsável pela reabsorção da água nos túbulos coletores nos rins. É secretado em decorrência do aumento da pressão osmótica ou da redução da pressão hidrostática sanguínea. A essa deficiência dá-se o nome de Diabetes Insipidus (CUNNINGHAN; KLEIN, 2003). Animais com esse tipo de diabete apresentam um aumento na excreção de água do organismo, denominada poliúria e também uma polidpsia compensatória, o que se observa no presente estudo onde os animais hipofisectomizados apresentaram um aumento no volume urinário e no consumo diário de água.

Outra hipótese para o aumento do consumo de água e produção urinária, principalmente nos animais que tiveram a associação das duas substâncias, está interligada com o aumento de proteína bruta na carcaça, tendo em vista que quanto maior a quantidade de massa muscular, maior será o teor de umidade, e quanto maior a umidade, maior a demanda pela ingestão de água.

Sabe-se que determinadas doses de ractopamina geram alterações cardíacas por meio da ativação ou dessensibilização dos receptores beta adrenérgicos. Em alguns estudos, como o de Catalano et al. (2012), as alterações observadas no coração foram dose independente. No seu estudo com suínos a alta dose de ractopamina gerou uma diminuição cardíaca, o que condiz com o presente estudo no qual os animais apresentaram um menor peso cardíaco quando comparados ao grupo controle. Essa alteração pode ser devido à dessensibilização ou sub-regulação de receptores beta-adrenérgicos cardíacos. $\mathrm{O}$ uso do $\mathrm{GH}$ proporcionou o peso cardíaco menor quando comparado ao controle. Isso provém da maior síntese de proteínas na carcaça, aumentando o peso muscular dessa em uma proporção maior que o crescimento dos órgãos viscerais, o que explica também o menor peso relacionado ao baço.

Com relação ao peso intestinal, de acordo com Catalano et al. (2012), a ractopamina pode causar uma diminuição na concentração do hormônio da tireoide T3, responsável pela regulação térmica do organismo, por estimular de forma cruzada os receptores alfa adrenérgicos, então o intestino tende a aumentar para tentar equilibrar a temperatura corporal do animal.

Outra hipótese para o peso intestinal seria o fato de que com o uso desse modificador, há uma maior produção de proteína no tecido muscular animal, o que gera aumento intestinal por necessidade de captação de nutrientes pelo organismo. Essa necessidade pode ser devido à maior concentração de proteína bruta na carcaça quando comparada aos animais que não receberam ractopamina. Com essa melhora metabólica o organismo tende a reter maior quantidade de nitrogênio sendo com 
isso uma menor quantidade excretada pelos rins. Dessa forma, esse órgão não tem a necessidade de se expandir para conseguir realizar sua função. Neste estudo houve a diminuição do peso renal nos animais que fizeram uso do modificador metabólico, confirmando o resultado encontrado por Ferreira et al. (2006), que utilizaram suínos intactos e doses de ractopamina muito menores.

Os animais hipofisectomizados apresentaram o fígado e o baço menores que os animais controle não hipofisectomizados, o que pode ser oriundo da deficiência de GH, relacionado ao metabolismo celular. Novos estudos precisam ser realizados para elucidar as diferenças metabólicas presentes em animais hipofisectomizados.

O aumento pulmonar presente nos animais tratados com ractopamina provavelmente ocorre pelo aumento de frequência respiratória causada pela administração do agonista, que gera um aumento do metabolismo animal. Novos estudos precisam ser realizados para se observar a relação existente entre o uso ou não do hormônio de crescimento associado ao peso pulmonar.

Vários autores verificaram a ação da ractopamina e do hormônio de crescimento (GH) quanto ao aumento da síntese proteica muscular, por estimular a expressão de RNA mensageiro, a redução da degradação e aumento da absorção de aminoácidos, além do aumento da lipólise no tecido adiposo (GUNAWAN et al., 2007; VIJAYAKUMAR et al., 2010). A ractopamina, agonista beta adrenérgico, aumenta a massa muscular pelo estímulo da capacidade glicolítica do músculo aumentando sua síntese proteica, além de aumentar a taxa lipolítica pela fosforilação da enzima lipase hormônio sensível (LHS) (MERSMANN, 2002). O GH, apresentando receptores específicos no tecido adiposo, atua de forma direta na lipólise também pelo aumento da atividade da enzima LHS (CRUZAT et al., 2008). A diminuição do extrato etéreo na carcaça dos animais tratados tanto com o GH e com o agonista beta-adrenérgico, mostra também que a associação das duas substâncias provocou maior diminuição nos valores dessa variável pela soma das ações lipolíticas e/ou de redução da lipogênese, confirmando também que o GH aumenta a eficiência dos receptores beta-adrenérgicos (CRUZAT et al., 2008).
Os resultados apresentados neste trabalho confirmam o esperado aumento da síntese proteica e a diminuição do extrato etéreo nos animais tratados com a ractopamina e GH.

O aumento da porcentagem de proteína e a diminuição da porcentagem de gordura dos animais tratados com ractopamina explicam o aumento na umidade, pois a maior proporção de água do organismo se encontra a nível muscular quando comparada ao tecido adiposo.

Os níveis de colesterol total foram maiores nos animais que receberam a ractopamina quando comparados aos grupos que não receberam. Uma hipótese para esse resultado é o aumento da produção de colesterol HDL, o qual representa $70 \%$ do colesterol de ratos (SOUSA et al., 2002), estimulada por receptores agonistas beta-adrenérgicos. Com este trabalho não foi possível identificar as causas específicas dessa alteração, havendo a necessidade de se realizar mais estudos envolvendo esse parâmetro.

No presente estudo, os níveis de triacilglicerois no tratamento com a associação do $\mathrm{GH}$ e ractopamina se mostraram menores que o nível do tratamento controle não hipofisectomizado. Uma hipótese para essa diminuição é a redução da síntese de triacilglicerois hepáticos (lipogênese hepática) pelo uso concomitante do $\mathrm{GH}$ com o agonista beta adrenérgico, o que gera uma liberação menor desses triacilglicerois para o sangue.

Um dos efeitos do hormônio do crescimento está relacionado com a hiperglicemia, pelo estímulo da produção hepática de glicose (OLIVEIRA et al., 2011). Animais com deficiência de GH normalmente apresentam uma menor concentração de glicose sanguínea, o que pode ser observado no experimento, nos quais os animais hipofisectomizados apresentaram, de uma maneira geral, menores níveis glicêmicos quando comparados aos animais controle, sendo que os animais tratados com o GH apresentaram uma média maior quando comparado aos animais não tratados. Outra hipótese para a menor glicemia dos grupos hipofisectomizados está relacionada com a função do IGF-1 o qual estimula a captação de glicose pela ativação do GLUT-4 (transportadores de glicose tipo 4) no tecido muscular esquelético (OLIVEIRA et al., 2011), pois animais que apresentaram maior concentração de IGF 
1 tiveram menor glicemia e vice-versa. Os animais que receberam a ractopamina apresentaram menor glicemia quando comparados aos animais que não receberam essa substância. Uma hipótese para essa diferença é o aumento da transcrição de glicogênio sintetase no músculo estimulado por agonistas beta adrenérgicos, aumentando a captação de glicose sanguínea para a produção de glicogênio muscular (GUNAWAN et al., 2007).

O IGF-1, a principal somatomedina que mede as funções do $\mathrm{GH}$, tem como seu principal local de produção, o fígado, sendo estimulada pela liberação do GH. Muitas dúvidas a respeito de suas funções ainda não foram esclarecidas, mas alguns trabalhos, como o de Yakars et al. (1999), mostram que sua produção não é realizada somente no fígado. Yakars et al. (1999) mostraram que os animais apresentam outros locais (ainda não esclarecidos) de produção de IGF 1 além do fígado, e que sua produção é significativa. Essa produção, provavelmente, ocorre de forma autócrina e parácrina independente da estimulação do hormônio de crescimento (OLIVEIRA et al., 2011). Isso condiz com o presente estudo, o qual de uma forma geral não revelou diferenças entre os animais hipofisectomizados e o tratamento controle.

Os grupos de animais que receberam a ractopamina apresentaram menor concentração sanguínea de Peptídeo C quando comparados aos grupos que não fizeram o uso dessa substância. Uma hipótese para essa diferença é a presença de receptores beta-adrenérgicos nas células $\alpha$ das ilhotas pancreáticas, assim sendo, a ractopamina pode apresentar efeito sobre a liberação de glucagon, o qual é antagônico à insulina. Em animais normais essa relação insulina/glucagon tende ao equilíbrio, o que não se observa em animais hipofisectomizados, no qual um desses fatores pode sobrepor-se ao outro.

\section{Agradecimentos}

À FAPEMIG, à CAPES e ao CNPq, pelos auxílios financeiros.

\section{Referências}

APPLE, J. K.; RINCKER, P. J.; MCKEITH, F. K.; CARR, S. N.; ARMSTRONG, T. A.; MATZAR, P. D. Meta-analysis of the ractopamina response in finishing swine. Professional Animal Scientist, Champaign, v. 23, n. 3, p. 179-196, 2007.

BAUER, A.; LACORN, M.; CLAUS, R. Effects of two levels of feed allocation on IGF-I concentrations and metabolic parameters in GnRH-immunized boars. Journal of Animal Physiology and Animal Nutrition, Berlin, v. 93, p. 744-753, 2009.

BUONOMO, F. C.; BAILE, C. A. The neurophysiological regulation of growth hormone secretion. Domestic Animal Endocrinology, Auburn, v. 7, n. 4, p. 435-450, 1990.

CANTARELLI, V. S. Ractopamina em rações para suínos em terminação com alimentação à vontade ou restrita. Lavras: UFLA, 2007. 108 p.

CATALANO, D.; ODORE, R.; AMEDEO, S.; BELLINO, C.; BIASIBETTI, E.; MINISCALCO, B.; PERONA, G.; POLLICINO, P.; SAVARINO, P.; TOMASSONE, L.; ZANATTA, R.; CAPUCCHIO, M. T. Physiological changes related to the use of ractopamine in swinw: clinical and pathological investigations. Livestock Science, Amsterdam, v. 144, p. 74-81, 2012.

CERANOWICZ, D.; WARZECHA, Z.; DEMBINSKI, A.; CERANOWICZ, P.; CIESZKOWSKI, J.; KUSNIEZ-CABALA, B.; TOMASZEWSKA, R.; KUWAHARA, A.; KATO, I. Role of hormonal axis, growth hormone - IGF-1, in therapeutic effect of ghrelin in the course of cerulein-induced acute pancreatitis. Journal of Physiology and Pharmacology, Krakow, v. 61, n. 5, p. 599-606, 2010.

CRUZAT, V. F.; JUNIOR, J. D.; TIRAPEGUIL, J.; SCHNEIDER, C. D. Hormônio do crescimento e exercício físico: considerações atuais. Revista Brasileira de Ciências Farmacêuticas, São Paulo, v. 44, n. 4, p. 549-562, 2008.

CUNNINGHAN, J. G.; KLEIN, B. G. Tratado de fisiologia veterinária. 4. ed. Rio de Janeiro: Guanabara Koogan, 2008. 590 p.

DEL RINCON, J. P. Growth hormone regulation of p85- expression oad Phosphoinositide 3-kinase activity in adipose tissue: mechanism for growth hormone mediated insulin resistance. Diabetes, New York, v. 56, p. 1638-1646, 2007.

DUBROVIN, L. C.; LIU, C. Y.; MILLS, S. E. Insulin binding to use adiposities exposed to clenbuterol and ractopamine in vitro and in vivo. Domestic Aminal Endocrynology, Beeville, v. 7, n. 1, p. 103-109, 1990.

ENGELKING, L. R. Textbook of veterinary physiological chemistry. 2. ed. Oxford: Elsevier, 2011. 607 p.

FERREIRA, R. A.; OLIVEIRA, R. F. M.; DONZELE, J. L.; ARAUJO, C. V.; SILVA, F. C. O.; VAZ, R. G. M. V.; REZENDE, W. O. Redução da proteína bruta da ração e suplementação de aminoácidos para suínos machos dos 15 aos $30 \mathrm{~kg}$ mantidos em ambiente de alta temperatura. Revista Brasileira de Zootecnia, Viçosa, v. 35, n. 3, p. 1056-1062, 2006.

FRYSTYK, J. Free insulin-like growth factors - measurements and relationships to growth hormone secretion and glucose homeostasis. Growth Hormone \& IGF Research, London, v. 14, p. 337-375, 2004.

GONZALEZ, F. H. D.; SILVA, S. C. Introdução a bioquímica clínica veterinária. Porto Alegre: UFRGS, 2006. 360 p. 
GUNAWAN, A. M.; RICHERT, B. T.; SCHINCKEL, A. P.; GRANT, A. L.; GERRARD, D. E. Ractopamine induces differential gene expression in porcine skeletal muscles. Journal of Animal Science, Champaign, v. 85, p. 2115-2124, 2007.

HAUSMAN, D. B.; MARTIN, R. J.; VEENHUIZEN, E. L.; ANDERSON, D. B. Effect of ractopamine on insulin sensitivity and response of isolated rat adiposities. Journal of Animal Science, Champaign, v. 67, p. 1455-1464, 1989.

JOHANSEN, T.; LAURINO, C.; BARRECA, A.; MALMLOF, K. Reduction adiposity with prolonged growth hormone treatment in old obese rats: effects on glucose handling and early insulin signaling. Growth Hormone \& IGF Research, London, v. 15, p. 55-66, 2005.

KIM, Y. S.; LEE, T. H.; CHOIF, Y. J. Effect of intermittent and stepwise administration of a beta-adrenergic agonist, L644,969, on rat growth performance and skeletal muscles. Camparative Biochemistry and Physiology, Oxford, v. 1, n. 2, p. 127-132, 1990.

LIU, C. Y.; GRANT, A. L.; KIM, K. H.; JI, S. Q.; HANCOCK, D. L.; ANDERSON, D. B.; MILLS, S. E. Limitations of ractopamine to affect adipose tissue metabolism in swine. Journal of Animal Science, Champaign, v. 72, p. 62-67, 1994.

LIU, C. Y.; MILLS, S. E. Decreased insulin binding to porcine adipocytes in vitro by beta-adrenergic agonists. Journal of Animal Science, Champaign, v. 68, p. 1603-1608, 1990.

MAURAS, N.; HAYMOND, M. W. Are the metabolic effects of GH and IGF-1 separable? Growth Hormone \& IGF Research, London, v. 15 , p. 19-27, 2005.

MERSMANN, H. J. Beta-Adrenergic receptor modulation of adipocyte metabolism and growth. Journal of Animal Science, Champaign, v. 80, Suppl. 1, p. 24-29, 2002.

MILLS, S. E. Implications of feedback regulation of beta-adrenergic signaling. Journal of Animal Science, Champaign, v. 80, Suppl. 1, p. 30-35, 2002.

MILLS, S. E.; KISSEL, J.; BIDWELL, C. A.; SMITH, D. J. Stereoselectivity of porcine \{beta\}-adrenergic receptors for ractopamine stereoisomers. Journal of Animal Science, Champaign, v. 81, n. 1, p. 122-129, 2003.

MOODY, D. E.; HANCOK, D. L.; ANDERSON, D. B. Phenethanolamine repartitioning agents. In: MELLO, J. P. F. D. (Ed.). Farm animal metabolism and nutrition. New York: CAB, 2000. p. 65-95.

OLIVEIRA, C. R. P.; MENEGUZ-MORENO, R. A.; OLIVEIRA, M. H. A.; MANUEL, H.; BARRETO-FILHO, J. A. S. Papel emergente do eixo GH/IGF-1 no controle cardiometabólico. Arquivo Brasileiro de Cardiologia, São Paulo, v. 97, n. 5, p. 434-439, 2011.
PAGE, K.; HARTZELL, D. L.; LI, C.; WESTBY, A. L.; DELLAFERA, M. A.; AZAIN, M. J.; PRINGLE, T. D.; BAILE, C. A. Adrenergic receptor agonists increase apoptosis of adipose tissue in mice. Domestic Animal Endocrinology, Auburn, v. 26, p. 23-31, 2004.

ROSENDAL, L .; LANGBERG, H.; FLYYBJERG, A.; FRYSTYK, J.; ORSKOV, H.; KJAER, M. Physical capacity influences the response of insulin-like growth factor and its binding proteins to training. Journal of Applied Physiology, Washington, v. 93, p. 1669-1675, 2002.

SEE, M. T.; ARMSTRONG, T. A.; WELDON, W. C. Effect of a ractopamine feeding program on growth performance and carcass composition in finishing pigs. Journal of Animal Science, Champaign, v. 82, n. 8, p. 2474-2480, 2004.

SOUSA, R. V.; SANTOS, P. C. F.; BAMBIRRA, E. A.; VIEIRA, E. C.; LEITE, J. Nutritional characteristics of amazonian fish fat (Colossoma macropomum) and its effect on lipid metabolismo f rats fed hypercholesterolemic diets. Ciência e Tecnologia de Alimentos, Campinas, v. 22, n. 1, p. 88-93, 2002.

SUGA, H.; KADOSHIMA, T.; MINAGUCHI, M.; OHGUSHI, M.; SOEN, M.; NAKANO, T.; TAKATA, N.; WATAYA, T.; MUGURUMA, K.; MIYOSHI, H.; YONEMURA, S.; OISO, Y.; SASAI, Y. Self-formation of functional adeno-hypophysis in treedimensional culture. Nature, London, v. 480, p. 57-64, 2011.

VIJAYAKUMAR, A.; NOVOSYADLYY, R.; WU, Y.; YAKAR, S.; LEROITH, D. Biological effects of growth hormone on carbohydrate and lipid metabolism. Growth Hormone \& IGF Research, London, v. 20, p. 1-7, 2010.

WATANABE, P. H.; THOMAZ, M. C.; PACOAL, L. A. F.; RUIZ, U. S.; DANIEL, E.; CRISTANI, J. Ractopamine in diets for finishing gilts. Revista Brasileira de Zootecnia, Viçosa, v. 40, n. 4, p. 827833, 2011.

WEBER, T. E.; RICHERT, B. T.; BELURY, M. A.; GU, Y.; ENRIGHT, K.; SCHINCKEL, A. P. Evaluation of the effects of dietary fat, conjugated linoleic acid, and ractopamine on growth performance, pork quality, and fatty acid profiles in genetically lean gilts. Journal of Animal Science, Champaign, v. 84, n. 3, p. 720732, 2006.

YAKAR, S.; LIU, J.-L.; STANNARD, B.; BUTLER, A.; ACCILI, D.; SAUER, B.; LEROITH, D. Normal growth and development in the absence of hepatic insulin-like growth factor I. Proceedings of the National Academy of Sciences of the United States of America, Washington, v. 96, p. 7324-7329, 1999. 